A AUTORA

Denise Lino de Araújo

Professora do Departamento de Letras, Centro de

Humanidades, da Universidade Federal da Paraíba.

E-mail: d.lino@bol.com.br

\title{
TV COMO INSTÂNCIA DE LETRAMENTO
}

Intertextualidade entre os discursos da TV e da escola desafiam ambas as instâncias a repensarem seus campos específicos

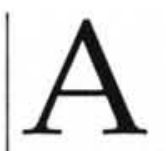

propósito dos 50 anos da televisão brasileira, várias comemorações, lançamentos de livros, exposições e séries de TV foram organizadas com o objetivo de fazer uma retrospectiva da produção nessas cinco décadas e, ao mesmo tempo, avaliar o papel social desse veículo de entretenimento e de informação, largamente inscrito no cotidiano do país. As comemorações seguiram a regra geral da homenagem e a crítica permaneceu no seu papel de especulação. Entretanto, em quase todos esses eventos, mesmo que os críticos se recusem a discutir $o$ assunto, inevitavelmente, ele vem à baila: a televisão aberta é educativa? Sim? Não? Deve fazer isto? Como fazer?

Embora a função precípua da televisão comercial não seja a educação, não se faz necessário recorrer a uma pesquisa para constatar junto a telespectadores de diferentes classes sociais e com variadas experiências culturais o que eles aprenderam com a televisão. O Museum of television $\&$ radio de Nova York apresentou no segundo semestre de 2000, no canal Bravo, a série Influences, na qual a cada programa semanal uma personalidade de grande destaque social e cultural daquela cidade e de outras dos EUA revelava a importância da TV em sua formação. A edição de cada capítulo cuidava de associar imagens que justificavam os argumentos ${ }^{1}$.

Essa idéia de alguma forma foi a que norteou a elaboração do programa $T V e$ conhecimento, da TV Cultura, exibido em 30 de novembro de 2000 , dentro da série TV 50 anos. O programa coletou informações tanto de telespectadores quanto de pessoas diretamente relacionadas à TV, entre elas críticos, autores, atores, apre-

1. DÁVILA. Sergio. Museu em Nova York tem 120 mil programas. Folha de S. Paulo. São Paulo, 27/08/2000. 
sentadores, diretores. No entanto, dispensou a presença de professores e, por isso mesmo, deixou de contar com as opiniões de quem lida cotidianamente com a formalização do conhecimento e, por conseguinte, poderia indicar, por experiência própria, qual tipo de conhecimento oferecido pela televisão pode ser relacionado ao sistematizado pela escola. A esse respeito manifestou-se Johnny Saad, presidente da Rede Bandeirantes de Televisão, ao afirmar que "o professor hoje não pode mais dar aula apenas com quadro e giz ou apenas falar do que aconteceu no Egito cinco mil anos atrás quando as crianças de hoje já se formam sob a cultura plástica e visual da televisão" ${ }^{2}$.

Em que pese a verdade do que disse Saad, essa afirmativa não deve deixar de ser entendida como um enunciado assinado e datado. Primeiro, porque se trata da fala do presidente de uma das grandes redes de televisão do país, apenas por isso já há que se levar em consideração os interesses que ele certamente deve ter, assim como a sua não isenção em relação ao tema. Por outro lado, essa afirmativa traz também a marca dos 50 anos da televisão no Brasil. Dita agora, tem mais peso, dado que carrega a marca da "data redonda" .

Pode-se ainda acusar Saad de estar de alguma sorte forjando uma espetacularização da sala de aula. Mas não se pode deixar de reconhecer que ele, assim como Freire $^{4}$ e Machado ${ }^{5}$, em épocas diferentes e por motivos diferentes, apontaram a televisão como um fato cultural do nosso tempo. Tanto é assim que talvez a própria espetacularização seja uma marca da nossa contemporaneidade. Gabler, estudando esse fenômeno, afirma que a "vida virou arte, de tal forma que as duas são agora indistintas uma da outra" ${ }^{\circ}$. O empresário das comunicações parece ter assumido essa posição sem os pudores que muitas vezes os professores apresentam para constatar o óbvio: não dá mais para ensinar só falando e usando giz e quadro.

Longe de creditar à opinião do presidente da Bandeirantes uma verdade insofismável, ela é tomada aqui como uma referência para a discussão a que se propõe este trabalho, qual seja a de que a televisão aberta pode ser tomada como um fator de letramento.

Em outras palavras, a pergunta central a ser discutida é: que tipo de conhecimento pode ser auferido com a TV?

Este trabalho tem como objetivo apresentar argumentos que visam a auxiliar uma discussão mais pedagógica sobre a relação entre televisão e conhecimento. Tem como pressupostos gerais a noção de linguagem como interação social e a noção de letramento como o processo de inserção no universo dos usos sociais da escrita, através de um contato sistemático

2. TV CULTURA. Série TV 50 anos. 30/11/2000.

3. No jargão jornalístico, as datas redondas são as terminadas em 0 ou 5. Dizem os jornalistas que essas datas "costumam dar matéria".

4. FREIRE, Paulo. Não sou contra a televisão. In:

2. Rio de Janeiro: Paz e Terra, 1984. p. 14.

5. MACHADO, Arlindo. A televisão levada a sério. São Paulo: Senac, 2000. p. 21.

6. GABLER, Neal. A sociedade bidimensional. In:

Companhia das Letras, 1999. p. 69. e GUIMARÃES, Sergio. Sobre Educação. Diálogos. v.

Vida, o filme. [Tradução Beth Vieira]. São Paulo: 
com uma pluralidade de formas de leitura e de tipos de texto socialmente valorizados, além daqueles puramente escolares. Os argumentos que sustentam tal objetivo estão dispostos nas quatro partes subseqüentes. Na primeira, a televisão é focalizada como um objeto de estudo e é brevemente resenhada a principal tendência contemporânea de abordagem desse assunto. Na segunda, são expostos alguns dos fundamentos teóricos que me permitem afirmar ser a televisão uma instância enunciativo/discursiva. Na terceira, são contrastadas a cultura letrada e a cultura midiática. Na quarta parte, são apresentadas as características da escola e da televisão como instâncias de letramento.

\section{TELEVISÃO: OBJETO DE ESTUDO}

A postura dos meios acadêmicos em não reconhecer a televisão como um fenômeno cultural, antropológico e lingüístico fez com que a TV, por muito tempo, não fosse considerada um objeto de estudo.

Atualmente, as pesquisas sobre a televisão, sobretudo as realizadas de uma perspectiva antropológica, tanto no Brasil quanto no exterior, estão voltadas para entender como e por quê a TV influencia e é influenciada. Nesse sentido, procuram entendê-la não só como meio de difusão, mas também como meio de produção e de reprodução da cultura e da linguagem de uma sociedade.

Embora outras correntes estejam em atuação, a grande ênfase dos estudos atuais é a da recepção, que é exatamente o pólo mais obscuro do processo de interlocução estabelecido pela TV, exatamente porque é heterogêneo, difuso e não é de fácil acesso quando se quer realmente saber o que as pessoas pensam da televisão ou como este meio de comunicação influencia as suas vidas. Para Ien $\mathrm{Ang}^{7}$, a análise da recepção interessa-se pelos modos como as pessoas ativas e criticamente dão sentido e criam a sua própria cultura em vez de passivamente absorverem os sentidos impostos. Assim sendo, esses estudos modificam radicalmente a visão de uma audiência pacífica e a-crítica.

Essas abordagens sobre recepção muito têm se beneficiado das técnicas etnográficas de coleta de dados, típicas das pesquisas antropológicas, muito embora tais estudos possam também ser realizados com os chamados grupos de controle - grupos de discussão. Na abordagem etnográfica, o foco é a entrevista com os espectadores em suas próprias casas, numa imersão na vida diária. Desloca-se, assim, com essa perspectiva, a dicotomia texto/ conteúdo, tantas vezes utilizada na análise da TV, para focalizar algo mais amplo, segundo Spitulnik ${ }^{8}$, as práticas da audiência, a sua diversidade, os usos da mídia, a sua multivocalidade, a indeterminação dos seus textos. Nesse caso, a televisão é examinada como um dinâmico lugar de luta por representações e um lugar complexo onde as subjetividades são construídas e as identidades são contestadas.

Não obstante a probabilidade de interferência do pesquisador, cujos limites de atuação precisam ser muito bem circuns-

7. ANG, Ien. Culture and communication: towards an ethographic critique of media consumption in the transnational media sistem (Cultura e comunicação: para uma crítica etnográfica dos meios no consumo do sistema transnacional da midia.). European Journal of communication. London: Sage, v. 5, 1990, p 242.

8. SPITULNIK. Debra. Antropology and mass media. Annual review of antropology. (Antropologia e meios de comunicação. Revista Anual de Antropologia.) n. 22, 1993. p. 298. 
critos (se é que isto é possível neste tipo de atividade acadêmica), são essas pesquisas que têm evidenciado as contradições dos telespectadores. É comum muitos daqueles que dizem não assistir a determinados programas de TV serem flagrados assistindo a eles ou revelarem-se muito bem informados sobre o seu andamento. Por outro lado, muitos afirmam não ter opinião formada sobre uma série de programas que consomem indiscriminadamente.

Essas contradições dão margem para se pensar que a chamada recepção ativa da $\mathrm{TV}$, conforme detectado pelos estudos etnográficos, não é tão ativa assim, ou pelo menos é mais ativa em determinados momentos e talvez em relação a determinados temas.

Talvez estes dois aspectos da recepção - passividade e atividade crítica - sejam duas faces indissociáveis do processo, constrangidas por pressões sócio-individuais, sempre prontas a reagir. Michel de Certeau adverte sobre a passividade do leitor, afirmando: "onde o aparelho científico é levado a supor as multidões transformadas pelas conquistas e as vitórias de uma produção expansionista, é sempre bom recordar que não se devem tomar os outros por idiotas" ${ }^{\prime 9}$. Guardadas as devidas proporções, tal afirmação é indicativa de que a passividade do telespectador deve ser relativisada.

Superado, então, o foco tradicional de ver a TV como um agente que molda a sociedade e mais especificamente o telespectador, como se este pudesse ser influenciado direta e decisivamente tão logo seja acionado o aparelho de televisão, abre-se a possibilidade de vê-la como uma instância enunciativodiscursiva e, portanto, um lugar de representações subjetivas múltiplas, o que não significa dizer que tais representações sejam aceitas pelos telespectadores de forma incontestável. Essa noção será apresentada a seguir.

\section{TELEVISÃO: UMA INSTÂNCIA ENUNCIATIVO-DISCURSIVA}

O conceito de instância enunciativodiscursiva aqui adotado advém dos estudos de Benveniste ${ }^{10}$ e de Bakhtin ${ }^{11}$. De acordo com o primeiro, a linguagem é vista como uma atividade social, como forma de ação, como lugar de interação entre sujeitos, num determinado contexto social de comunicação. É, pois, na e pela linguagem que são veiculadas as informações, expostos os sentimentos. É, enfim, com a linguagem que se pode agir sobre o mundo e se constituir como sujeito.

\footnotetext{
9. CERTEAU, Michel de. A Invenção do Cotidiano. Artes de fazer. [Tradução Ephraim Ferreira Alves]. Petrópolis, Rio de Janeiro: Vozes, 1994. p. 273.

10. BENVENISTE, Émile. Problemas de Lingüística Geral I. [Tradução Maria da Glória Novak e Maria Luiza Neri] $3^{a}$ ed. Campinas: Pontes/Unicamp, 1991. Guimarães et al]. Campinas: Pontes/Unicamp, 1989. 
De acordo com Bakhtin, a linguagem pode ser entendida como um locus de atuação social e não como mera representação do mundo. Para melhor entender essa instância, o autor informa que "o centro organizador de toda a expressão não é o interior, mas o exterior que está situado no meio social que envolve o indivíduo"'2 . Diz ainda Bakhtin "a enunciação é produto da interação social, quer se trate de um ato de fala determinado pela situação imediata ou pelo contexto mais amploque constitui o conjunto das condições de vida de uma determinada comunidade lingüística"13.

Essas explicações podem ser melhor entendidas quando se leva em consideração que, como instância enunciativa, a linguagem não se restringe a mera verbalização. Cada enunciação vai receber as características, as marcas da ideologia a que está vinculada. Utilizando-nos dos termos de Foucault ${ }^{14}$, são as "formações discursivas" típicas de cada instituição, de cada esfera de atuação social, que emprestam ao exercício discursivo uma "tonalidade" ideológica e expressiva. E cada vez que o enunciador, seja ele um cidadão, uma entidade ou organização, põe em funcionamento o sistema discursivo, ele visa a colonizar quem o ouve, da mesma forma que sofre a ação colonizadora deste. A síntese desse exercício é o que Benveniste chama de enunciação. Lembro, porém, que mais do que enunciar é preciso fazê-lo de uma posição discursiva.

Tanto Benveniste quanto Bakhtin falam primariamente de instâncias enunciativas que se instauram entre dois enunciadores, logo, em presença, face-a-face. Entretanto, o teórico russo já aponta para a constituição de uma instância enunciativa em que o Outro (ou o TU nas palavras de Benveniste) aparece representado. Diz textualmente esse autor: "a enunciação é produto de dois indivíduos socialmente organizados e mesmo que não haja um interlocutor, real, este pode ser substituído pelo representante médio do grupo ao qual pertence o locutor"15. Provavelmente, Bakhtin inferiu essa concepção do representante médio a partir dos estudos sobre a poética de Dostoievsky e não a partir de uma relação com a mídia, todavia ela se aplica ao processo comunicativo aqui focalizado. A interação verbal entre a televisão e os telespectadores norteia-se por esse pressuposto de substituir o interlocutor real por um representante médio, mais especificamente por uma descrição desse interlocutor segundo a sua classe social e o seu grau de instrução aferido pelas pesquisas. Cabe observar que nem os meios de comunicação de massaa televisão em especial - pensam num interlocutor abstrato, muito menos Bakhtin. Ele próprio alertou: "não pode haver interlocutor abstrato; não teríamos linguagem comum com tal interlocutor, nem no sentido próprio nem no sentido abstrato" ${ }^{16}$. Por isso, há a necessidade de uma representação.

Aplicadas as noções de instância enunciativo-discursiva de Benveniste, Bakhtin e Foucault à televisão, verifica-

12. BAKHTIN, Mikhail. A interação... op. cit, p. 121

13. BAKHTIN, Mikhail. A interação... op. cit. p. 121.

14. FOUCAULT, Michel. A ordem do discurso. [Tradução Laura Fraga de Almeida Sampaio]. 5.ed. São Paulo: Loyola, 1999. 79 p.

15. BAKHTIN, Mikhail. A interação verbal. ...op. cit. p.112.

16. BAKHTIN. Mikhail. A interação ...op. cit. 
mos que este veículo de comunicação é também uma instância enunciativodiscursiva nos moldes aqui descritos. Entretanto, a característica de duelo para assunção da enunciação, por parte de um dos enunciadores, perde a sua essência, pois há, num primeiro momento, apenas a emissão de um deles, no caso os que produzem a programação televisiva. Para captar o Outro, nesse caso os telespectadores - e isto é necessário pois do contrário não se pode falar num processo de comunicação muito menos de enunciação -, as redes desenvolvem estratégias para atraí-lo. Algumas delas são as pesquisas que aferem a audiência (prefiro dizer que estimam o número de aparelhos sintonizados), outras são toda sorte de recursos de marketing televisivo e, nesse caso, utilizam também os espaços no rádio, visto que, em muitos casos, atingem uma audiência maior do que a da TV e é próprio do veículo a dinamicidade e a participação. Afora isso, os telespectadores são captados através das pesquisas qualitativas que envolvem entrevistas e grupos de discussão, essas mais raras e com um número reduzido de participantes.

Assim pensada, a televisão configurase como uma instância enunciativodiscursiva, dinâmica, que pressiona e é pressionada pela sociedade. Um exemplo desse embate de forças em nosso país pôde ser identificado no programa Malu MuIher, produzido pela Rede Globo, no início da década de 80 , que levou ao ar uma discussão ainda de bastidores sobre o divórcio e as relações entre família/trabalho/afetividade típicas do universo feminino. Se se pode dizer que esta série televisiva pressionou uma sociedade católica e patriarcal a aceitar a dissolução do casamento, pode-se dizer também que a rede foi pressionada pela sociedade no que diz respeito ao impeachment do presidente Collor, em 1992.

Em face das manifestações populares pró-afastamento do chefe de governo, a Globo não pôde mais calar ou editar matérias como fez com o último debate entre o então candidato, Fernando Collor e Luiz Inácio Lula da Silva, seu concorrente.

Omitir-se naquele momento, noticiar superficialmente, sonegar fatos, igualava a Globo às forças mais reacionárias do país, relação não desejada para uma rede que deteve durante muito tempo a hegemonia no setor. Ademais, significaria responder com o silêncio a um instigante processo enunciativo.

\section{CULTURA LETRADA E CULTURA MIDIÁTICA}

A televisão põe em funcionamento todo um sistema discursivo, tornando-o ainda mais eficiente porque o associa ao sistema imagético e tem como resultado um produto sensorial provavelmente nunca dantes visto. É forçoso reconhecer que este sistema discursivo não se estabelece numa inocente solicitude, persegue o propósito da colonização e o faz a partir da perspectiva da cultura letrada, para a qual os modos de pensar, de agir, de organizar 
a sociedade, as relações comerciais, jurídicas, religiosas e escolares, entre outras, estão marcadas pela lógica da escrita.

Quando me refiro à lógica da escrita, estou apontando para o fato de que a escrita não é apenas mero registro, mas é o que Umberto Eco denomina de "uma máquina para produzir interpretações"17. Isto significa dizer que o fato e a informação, de um modo geral, até podem ser divulgados independentemente do texto escrito, ou seja, através de imagens, gestos etc., mas a sua análise e interpretação só têm repercussão e impacto quando escrita e publicizada. Vale salientar que integra também essa lógica a prática de outros registros e de documentação de diversas atividades.

Ao conjunto dessas práticas sociais, na sua forma de expressão mais clássica de publicação - os impressos de forma geral - denomino aqui de cultura letrada tradicional. $\mathrm{O}$ adjetivo "tradicional", neste caso, não tem a intenção de caracterizar pejorativamente tal cultura ou de indicar-lhe um caráter de desatualização; aponta apenas os seus principais veículos de difusão.

É por estar assentada nessa lógica que a televisão é essencialmente um veículo verbal, por mais que se utilize do sistema imagético não pode dispensar de todo o verbal e quando o faz, em breves e especiais momentos, sem dúvida é para chamar mais atenção, o que realça a importância da linguagem verbal nesse veículo.

A cultura letrada tradicional começou a ser revista na segunda metade do século $\mathrm{XX}$. Por um lado porque começou a buscar outras formas de divulgação, como o áudio-livro e o $e$-book, ao lado das clássicas formas impressas que têm procurado alternativas neste mesmo formato de divulgação; por outro lado, porque começa a ser, cada vez menos, a primeira cultura de referência para um grande número de pessoas. E nesse caso a questão central é: como chegar até elas, como levar a leitura até as pessoas?

No Brasil, o processo de letramento de muitos grupos sociais, num primeiro momento, se define e se constitui a partir do repertório da cultura midiática, que passa a ser para muitos a primeira (e confiável) fonte de referência e de informação.

Sem dúvida, já está posto para a sociedade um conflito intrínseco relacionado aos vários estágios de letramento atualmente vividos. De um lado, ainda o alto índice de analfabetismo; de outro, o processo de implantação e disseminação da escolarização. Concomitantemente, o processo que vai da escolarização à inserção na cultura letrada. Por fim, a imersão nessa cultura via outras agências de formação sem que a escola seja o agente direto desse processo. A respeito dessa situação, Citelli comenta: "Forjados na expansão colonial e vivendo o estatuto de periferia, muitos países latino-americanos apresentaram uma particularidade quanto à sua história cultural: passaram rapidamente do plano discursivo-verbal para o dos meios

17. ECO, Umberto. Reflexões sobre a escrita. Cadernos do Terceiro Mundo. [s.I.], n. 120, 1989. p. 38. 
audiovisuais. O livro, a escrita, a alfabetização - no sentido estrito do letramento como sinônimo de todo 'saber' e traço distintivo nas relações sociais não tiveram tempo de assentar-se, de democratizar-se antes da entrada massiva das tecnologias das imagens e da retransmissão sonora. Nesse atalho, os meios de comunicação ganharam força, evidência, importância e se tornaram, em muitas regiões do continente, fontes quase exclusivas da informação e da expressão do que passou a ser dado como pretenso padrão 'comum' de cultura"18 .

$\mathrm{Na}$ falta de estudos mais detalhados que ajudem a entender esse processo cultural, não só do Brasil mas da América Latina, e quem sabe até de outras partes do mundo, somos levados a pensar que a filogênese do letramento não se dá linearmente, mas avança aos saltos. Ainda está para ser investigada a repercussão cultural, a longo prazo, das supostas lacunas desse processo.

Desse entrechoque de forças que se sustentam mutuamente, assiste-se a uma mudança nas formas de receber/arquivar e referenciar as informações. Em nosso país, a expressão "deu na TV" tem hoje o estatuto de um argumento por autoridade, como se o veículo fosse infalível. Para alguns, isto parece até o prenúncio do fim, entretanto, segundo Eco, ao contrário do que se imaginava, esses meios de comunicação em imagem e som são uma marca da sociedade letrada, desenvolvem-se graças a ela e, em vez de substituírem o livro, trouxeram-no de volta ao centro da história. Argumenta esse autor que: “(...) antes um jovem tinha de ir ao ginásio e ler livros, para saber qual era a capital de de- terminado estado, ou ainda onde fica o Nepal, ou qual a extensão da União Soviética. Hoje, não, na televisão aparecem os mapas. Todos conhecemos o oeste americano de tê-lo visto no cinema, e pouquíssimo por ter lido sobre a história dos Estados Unidos (...) As novas gerações aprendem uma infinidade de coisas através dos meios que as assediam. Não se pode afirmar, portanto, que os livros são extremamente necessários. Mas existem limites na historiografia dos meios de comunicação de massa. Atrás das imperfeições dos meios de comunicação existe a carência da leitura. Aqui voltamos a um ponto curioso: atualmente, deixando de lado o livro, pode-se aprender muitas coisas que, entretanto, só são possíveis de ser ensinadas recorrendo-se ao livro. (....) No momento em que começou no mundo a civilização da visão (televisão), aumentou o número de livros, de jornais e de revistas. As forças centrífugas em relação ao livro são, no final de contas, forças centrípetas e produzem a necessidade de novo papel impresso" 19 .

Em suma, não se pode negar que esses veículos, notadamente a televisão, nascidos e estruturados sob o livro, são bons divulgadores da cultura letrada. Dada a sua peculiaridade de apresentá-la cada vez mais visual e sonorizada, bem como a construção de novos gêneros típicos dessa plástica que indissocia imagens e sons, como o videoclipe, é que constituem o que tem sido denominado de cultura midiática. Esta parece que, além de introduzir atualmente profundas modificações nas relações sociais, está inaugurando uma nova

18. CITELLI, Adilson. Comunicação e educação: a linguagem em movimento. São Paulo: Senac, 2000. p. 148.

19. ECO, Umberto. Reflexões sobre a escrita. Cadernos do Terceiro Mundo. [s.1.]. n. 120. 1989, p. 39. 
forma de "alfabetização". Parafraseando Ferrero $^{20}$, posso apontar com base nessas observações a existência de uma mídia literacy ou um processo de letramento via cultura midiática, com características muito próprias e que se revelam na disseminação das informações em imagem e som, no conhecimento das adaptações de obras da cultura letrada, ao lado de outras especialmente escritas e formuladas para este âmbito, na compilação de informações fragmentadas e difusas, na familiaridade com diversos gêneros televisuais, no caráter de entretenimento dado a todos os produtos e, entre outras, na indissociação entre informação e espetacularização.

Algumas características dessa cultura midiática são as relações e os trocas entre ela e a cultura letrada tradicional: trocas intensas e entremeadas. As relações de permuta/transformação/re-missão entre os textos impressos e os audiovisuais favorecem a intertextualidade entre a literatu$\mathrm{ra} /$ cinema, a TV/literatura, TV/cinema, cinema/TV/ quadrinhos, produção publicitária/música, poesia, informações científicas, entre tantas outras. Nesse caso, a principal conseqüência é uma maior produção escrita, todavia mais pulverizada e, muitas vezes, muito mais conhecida não exatamente por aquilo que se disse no texto primeiro, mas pelo que as adaptações e a crítica disseram. Para se ter uma dimensão clara dessa consequiência basta imaginar o número de pessoas que nunca leu, por exemplo, Tieta do Agreste mas conhe- ce a história porque assistiu à novela e/ou ao filme.

\section{Com efeito, assistimos a uma mudança histórica cujos reflexos atingem os usos da linguagem e as suas formas de veiculação e de divulgação.}

É paradigmático o sucesso da minissérie o Memorial de Maria Moura, baseado em livro homônimo da escritora Raquel de Queirós, que se tornou, depois da adaptação para TV, o mais conhecido livro dessa escritora, que já era conhecida, mas apenas de um determinado público. Devese à minissérie a estréia nacional da autora de $O$ quinze. Esse, sem dúvida, é também o caso de Romeu e Julieta, história que provavelmente é muito mais conhecida pelas inúmeras versões do que pelo original. Disso tudo o que permanece é a fonte, a referência, o autor. Se da perspectiva da cultura letrada tradicional há que se lamentar por isso, talvez, na sociedade que se esboça por trás da queda de tantos paradigmas da informação, o mais importante não seja exatamente ter lido, mas saber de que se trata, quem escreveu e, sobretudo, conhecer a referência, a fim de que possa ser encontrada quando se quiser ler. Uma dificuldade nessa cultura é ainda o acesso a determinadas produções. Algumas exibidas apenas uma vez tornam-

20. Ferrero refere-se com muita propriedade ao surgimento de uma computer literacy nas escolas de países latinoamericanos, depois da entrada dos computadores nessas instituições. Diz a autora que esses equipamentos perfeitamente integrados às escolas dos países do primeiro mundo não adentram as nossas sem que provoquem aí algumas alterações significativas na cultura local e nas formas de organização do cotidiano pedagógico. Ver em: FERRERO. E. La revolución informática y los procesos de lectura y escritura. Estudos Avançados. São Paulo: USP,v. I1, n. 29.1997. p. 281. 
se obras raras nas mãos das produtoras e redes exibidoras, ou quiçá de alguns aficcionados que, bem atentos, gravam em VHS. Com o avanço da Internet para a televisão, provavelmente a digitalização favorecerá a disponibilidade para consulta a esses acervos.

Melo mostra-se otimista com esses intercâmbios. Afirma que "sem dúvida o livro foi o maior beneficiário dessa operação em cadeia. Considerando que as massas detentoras de um nível mediano de escolarização não adquiriram hábitos permanentes de leitura, elas se sentem motivadas a recuperar essa habilidade cada vez que o cinema e a televisão reconstituem obras literárias ou científicas" ${ }^{21}$. O mercado editorial tem se esforçado para criar este hábito de "leitura casada", associando relançamentos de livros às adaptações desses para a $\mathrm{TV}^{22}$. Uma análise dessa iniciativa espera ainda a realização de estudos qualitativos sobre o tema.

Assim, a cultura midiática rompe as fronteiras da página impressa e de modo progressivo atinge um número cada vez mais significativo de pessoas que, de outra forma, seja porque não soubessem ler ou não gostassem, estariam à margem da cultura letrada. Do mesmo modo, parece estimular hábitos de leitura entre um determinado segmento de leitores. Em face disto, concordo com Ferrero, quando afirma que o modo de atuar frente a estes meios, em especial, frente a essas telas (a da televisão e/ou a do computador) pode afetar a relação com o impresso, não só na frequiência de uso, mas também no que é mais importante: no modo de relação com o impresso ${ }^{23}$. E isto me parece é uma tarefa que cabe também à escola.

\section{ESCOLA E TELEVISÃO COMO INSTÂNCIAS DE LETRAMENTO}

A alteração/ampliação cultural brevemente descrita na parte anterior tem seus desdobramentos no âmbito escolar. Enquanto instituição direcionada para a formalização e sistematização do conhecimento e, portanto, a principal instância de letramento na nossa sociedade, a escola tem, além de um discurso próprio, uma série de características básicas que ajudam a mantê-la tal como a conhecemos. São elas: o seqüenciamento e a ordenação de conteúdos em função do critério do mais simples para o mais complexo; distribuição de matérias segundo uma escala de horizontalização (repetição ao longo da trajetória escolar) e verticalização (aprofundamento à medida que o aluno avança na hierarquia escolar); a singularização das experiências (cada série/turma vivencia atividades que lhe são próprias); a centralização da palavra na fala do professor; a centralização da fonte de informação no livro didático. Além dessas características, à escola também cabe a função de ser uma guardiã da cultura letrada, muito embora o que se possa verificar em alguns casos é que essa cultura torna-se um simulacro. No caso do ensino de língua, por exemplo, o papel da

21. MELO, José Marques de Melo. Estímulos midiáticos aos hábitos de leitura. In.: BARZOTTO, Valdir e GHILARDI. M. Inês. Mídia, educação e leitura. Sâo Paulo: Anhembi Morumbi/ ALB. 1999, p. 45.

22. Uma aposta recente do mercado editorial é a publicação de rotciros, como se fez com a minissérie $A$ Invençâo do Brasil, e a publicação de making off. como o da série Aquarela do Brasil. Ambos publicados pela Editora Globo.

23. FERRERO, Emilia. La revolución informática ... op. cit. p. 281. 
escola tem sido muito mais o de ensinar as normas prescritivas dispostas em gramáticas do português padrão do que o de inserir os alunos no mundo da leitura e da escrita. Por vezes a própria escola - unidade de ensino - é em si mesma um simulacro tanto no que diz respeito à sua estrutura quanto ao seu funcionamento.

Malgrado as tentativas de manter-se alinhada ao seu discurso, a escola tem sido subsidiada, complementada, revista e em algumas situações até corrigida pelas informações que vêm da televisão, tanto da TV aberta quanto da TV educativa, ainda que o tempo de elaboração de um programa para a televisão seja infinitamente menor do que o tempo gasto para a elaboração do conhecimento científico que norteia o trabalho escolar. A essa afirmação logo se segue a pergunta: por quê? As respostas são ainda provisórias e caminham desde respostas unidirecionais, segundo as quais a televisão é manipuladora, para respostas mais pseudo-elaboradas que investigam estarem as causas do sucesso da televisão no Brasil, ligadas ao fato de ser este um país de real primazia do oral, conforme advertiu Kato ${ }^{24}$. Essas respostas esquecem que a televisão é sucesso em praticamente todo o mundo, independentemente de os países terem uma primazia do oral ou não. Talvez as causas desse sucesso tenham outra origem e estejam ligadas ao desejo de fruição e de entretenimento que, encarnado pela televisão, permitiu que ela adentrasse através dos meios técnicos e de modo efetivo pelo mundo sensorial. A explicação de Gabler para a fusão entre fantasia e realidade na televisão norte-americana ajuda a pensar esse fenômeno no Brasil. Diz esse autor que "se a televisão transformou em notícia qualquer coisa que tivesse os rudimentos de entretenimento, também transformou em entretenimento tudo aquilo que contivesse os rudimentos de notícia" ${ }^{25}$. É possível que essa relação hoje fluida (mas decorrente da força enunciativo-discursiva da televisão, segundo se pode inferir das palavras de Gabler) entre o que é notícia e o que é entretenimento já não seja mais percebida pelos telespectadores. Nesse sentido é que as "informações" mais diversificadas vão sendo armazenadas como conteúdos, a partir de critérios subjetivos, acredito. E que são recuperadas pela memória ou são relacionadas a outros conteúdos não necessariamente pela informação em si, mas pelas imagens, pela emoção que despertaram, pela associação com outras vivências.

\section{Comparativamente à escola, a} televisão é o seu antônimo, pois se pauta pela fragmentação de informações e de experiências.

Pode-se ver isto nos dois principais gêneros desse veículo. O telejornal não dispõe de grande espaço, portanto, quase nunca dá a notícia descrevendo-a em minudências, nem tem tempo para aprofundar uma análise, que ficará para o veículo impresso. $\mathrm{O}$ mais importante, no caso do telejornal, é

24. KATO, M. No mundo da escrita: uma perspectiva psicolingüística. São Paulo: Ática, 1986, p. 39. 
apresentar um panorama dos acontecimentos locais, regionais ou mundiais, destacando os mais relevantes, segundo a opinião de editores/financiadores. Já a telenovela é genuinamente fragmentária, sobretudo as brasileiras, que primam por cenas curtas, cujo corte se dá no ápice do desenvolvimento da trama, ou que são interrompidas para a inserção de ganchos secundários, adiando, então, o epílogo pelo máximo de tempo possível. Por outro lado, essa fragmentação é suportada, auxiliada e diluída pela repetição. Em termos de tempo, a telenovela está para o telejornal assim como um ano está para um segundo. Ainda que fragmentária e repetitiva é através dela que, muitas vezes, são discutidos temas de maior interesse social.

\section{TELEVISÃO E INTERTEXTUALIDADE}

A televisão é fundamentalmente um veículo repetitivo. Como é pensada para não deixar vazios, os programas e os seus blocos de apresentação são curtos e devem ser dinâmicos, portanto, apostam na repetição, daí porque as telenovelas têm um desenvolvimento lento. Essa característica também está presente nos telejornais. Apenas quem assiste a um telejornal diário é que tem a impressão da novidade. O telespectador habituado a assistir a mais de um, seja da mesma emissora, seja de outra, logo percebe a repetição de temas, de notícias, de imagens e de formas de dizer.

Além dessas características, Rocco defende que "a televisão tem uma produção absolutamente intertextual, seja porque a partir do texto básico visual e verbal é gerada uma série de textos impressos, que incluem desde o resumo dos capítulos das novelas e minisséries, pelas revistas de fofocas e até pelas teses acadêmicas. Por outro lado, essa intertextualidade se manifesta nas conversas espontâneas das pessoas em torno do que vêm assistindo na TV. Nessas ocasiões, não raro, discute-se sobre as temáticas, as razões, os formatos dos programas, imprimindo a essas conversas a força da própria interpretação que se constitui por meio dos significados redundantes, díspares, surpreendentes, que surgem impregnados de experiência prévia de cada sujeito telespectador que interage com a TV e com o outro com quem dialoga" 26 .

Essa característica da televisão consubstancia as observações anteriormente expostas sobre o fato de ser uma instância enunciativo-discursiva. Mais que isso, essa característica consolida a televisão como uma instância dialógica e polifônica, no sentido baklttiniano desses termos.

À defesa apresentada por Rocco convém acrescentar dois argumentos. O primeiro é o de que o principal produto da televisão brasileira tem a sua gênese no teleteatro, pois foi da adaptação de obras teatrais que nasceu a telenovela. Em vista disto, este é, desde a sua gênese, um gênero híbrido, adaptado e intertextual. E até hoje as obras adaptadas para a televisão têm alcançado grande repercussão junto ao público, ao lado daquelas que são especialmente escritas para a TV. No caso das novelas podemos citar os exemplos de Roque Santeiro e Gabriela. A primeira, 
baseada na peça homônima de Dias Gomes, censurada na época da ditadura, era uma comédia de costumes, que alcançou um dos maiores índices de audiência desses 50 anos de história da televisão no Brasil. E a segunda é uma adaptação de Walter George Durst para o romance homônimo de Jorge Amado sobre a decadência da zona cacaueira.

O segundo argumento é que, afora a interxtualidade presente nas telenovelas e minisséries, as redações dos telejornais são uma espécie de central de transformação de textos. Tanto os que chegam via agência de notícias, como os que são veiculados pelo rádio, como os já publicados nos jornais impressos servem de temas para novas telenotícias/ reportagens.

Por ser intertextual é que a televisão não está centrada numa fonte. Observe-se que uma das regras do telejornalismo é a testemunhalidade, isto é, as matérias devem ser cobertas de modo a dar voz às partes interessadas, mesmo que essa voz seja de 30 segundos, em média. Ademais, a opinião de especialistas é importante, assim como a dos comentaristas e dos âncoras, que já se multiplicam no telejornalismo brasileiro.

Outras características singularizam a televisão, entretanto a que se denomina de concomitância de experiências destaca-se entre as demais visto que tem uma relação de contraposição direta com as experiências de escolarização. Enquanto a escola, conforme dissemos, prima pela singularização das experiências, na televisão, os telespectadores de diferentes idades têm a oportunidade de vivenciar, ao mesmo tempo, uma mesma experiência. Quebram-se, portanto, as barreiras entre o que é "história de criança" e o que "não é”. E não só o que diz respeito a ser história de criança, mas sobretudo o que diz respeito à disseminação de uma gama de informações antes somente apresentadas segundo os critérios de seqüenciação, horizontalização e verticalização.

As experiências de crianças, de adolescentes, de adultos e de idosos estão mais próximas, seja porque juntos assistem aos mesmos programas, seja porque, se não o fazem fisicamente próximos, têm os seus interesses aproximados pela linguagem da televisão.

A despeito dessas características (ou talvez até por causa delas) - fragmentação, repetição, intertextualidade e concomitância de experiências - significativamente diferentes das características da escola, que muitas experiências práticas vêm mostrando ${ }^{27}$ e que consolidam os argumentos aqui levantados, é que os alunos passam a integrar e a relacionar de uma forma que ainda chamamos de "natural" - na falta de um termo mais técnico - as informações difundidas pela televisão com as que são apresentadas pela escola. Da mesma forma que outras experiências descrevem o movimento contrário a esse, qual 
seja o de relacionar as informações escolares às que são veiculadas pela mídia ${ }^{28}$.

Em função desses intercâmbios, muitos educadores têm apontado um caráter pedagógico para a televisão comercial. Guimarães e Freire ${ }^{29}$ concordaram em denominar essa instância enunciativodiscursiva de "escola paralela". Guimarães, ao dialogar com Paulo Freire, afirma que, no início dos anos 70, os seus alunos do ensino fundamental, quando instados a falar em sala de aula sobre o seu cotidiano, freqüentemente relatavam o que viam na televisão e ouviam no rádio. Paulo Freire, ao comentar essa observação não apenas a endossa, mas acrescenta que a escola "é estática perto da dinâmica dos meios de comunicação de massa".

Esse depoimento revela duas observações importantes. A primeira diz respeito à presença do discurso da televisão concomitantemente ao da escola já no início dos anos 70, quando o número de televisores era bem menor que o de hoje. É desse período a expressão o "televizinho", cunhada para designar o fato de as pessoas se reunirem para assistir à TV. Já àquela época, ela rompia as fronteiras. Posteriormente, essa observação de Guimarães pôde ser comprovada por várias pesquisas, dentre os quais destacamos a de Citelli pelo fato de ter abrangido uma larga faixa de escolarização, em unidades situadas em diferentes locais da cidade de São Paulo. Essa pesquisa constatou um paradoxo no cotidiano escolar, pois ao mesmo tempo que em sala de aula havia uma ausência quase completa das linguagens institucionais não-escolares, próprias dos meios de comunicação de massa, a presença dessas linguagens era intensa nas conversas com os alunos e nos questionários por eles respondidos sobre os hábitos culturais. Afirma $o$ autor: "os alunos vivem uma intensa relação com as linguagens e com o conhecimento não sistematizados pelo discurso didático-pedagógico e promovem uma circulação que resulta em discussões, troca de experiências, estratégias de socialização, que contudo, se obliteram e preferem a zona do silêncio no momento sacralizado da sala de aula" ${ }^{30}$. No livro Comunicação e Educação, Citelli, voltando ao tema, reconhece que "... as experiências videotecnológicas já estão nas salas de aula, malgrado sob a forma de uma 'não-presença', pois tanto as crianças como os professores vivem num espaço social mediatizado por mensagens televisivas, radiofônicas, jornalísticas, etc., capazes de provocar alterações nos comportamentos, criarem referências para o debate público, influenciarem na tomada de decisões, além de revelarem, muitas vezes, os próprios limites do discurso pedagógico" ${ }^{31}$.

Cabe aqui fazer uma ressalva quanto à expressão "não presença" usada pelo autor. Acredito que diz respeito a uma presença informal, não materializada na abordagem didática, muito embora os temas divulgados pelos meios de comunicação

28. NAGAMINI, Eliana. Televisão, publicidade e escola. In.: CITELLI, Adilson (coord). Aprender e ensinar com textos não escolares. São Paulo: Cortez, 1997. p. 29-64.

29. FREIRE. Paulo e GUIMARÃ̉ES. Sergio. Sobre Educação. Diálogos. v. 2. Rio de Janeiro: Paz e Terra, 1984. p. $10-11$,

30. CITELLI, Adilson. Escola e meios de massa. In: res. São Paulo: Cortez, 1997. p. 19. (coord). Aprender e Ensinar com textos não escola-

31. CITELLI, Adilson. Comunicação e educação: ... op, cit. p. 140. 
de massa tenham sido detectados nas conversas paralelas às aulas e nos intervalos.

A segunda observação diz respeito ao fato de que Paulo Freire antecipou as considerações de Johnny Saad, apresentadas na introdução deste texto. Mesmo ele, que acreditava numa escola dinâmica, criativa e libertária, reconheceu o engessamento dessa instituição frente à dinâmica dos meios de comunicação de massa, particularmente da televisão.

Melo $^{32}$ adota para a TV a mesma definição dada por McLuhan: a TV proporciona uma educação coletiva que se dá numa sala de aula sem paredes. O problema dessa definição é o mesmo que caracteriza grande parte da obra de McLuhan para quem a televisão é, segundo a análise de Macha$\mathrm{do}^{33}$, congenitamente boa. Não obstante a visão excessivamente otimista de McLuhan, creio que Machado teria se referido não a um processo educativo no sentido estrito do termo, mas a um processo de instrução diferente do que é conduzido pela escola.

Baccega $^{34}$ vai mais longe do que todos esses autores ao reconhecer que o gênero telenovela é um dos mais educativos do veículo aqui focalizado, inclusive porque, segundo a autora, é nesse âmbito que são levantadas certas discussões para um público relativamente pouco informado.

Também Garrido ${ }^{35}$ apontou que, mesmo entre crianças pré-escolares, a TV, através dos desenhos animados, desempenha um papel socializador muito significati- vo, pois os argumentos desses filmes animados são o tema das conversas, das brincadeiras e são reproduzidos nas ações mais cotidianas desses alunos.

Essas poucas indicações são suficientes para apontar que pelo menos entre parte dos educadores há um consenso: a televisão, em especial alguns dos seus gêneros, desempenha uma função paralela à da escola, que pode também ser apontada como uma atividade (in)formativa/educativa.

Ao que esses educadores chamam de caráter pedagógico da televisão, nomeando-o de várias maneiras, prefiro denominar aqui de desencadeamento de um processo de letramento concomitante ao que é desenvolvido pela escola, sem ter, porém, o compromisso com a formalização e a sistematização do conhecimento. As minhas observações sobre esse processo me levam a identificar que o tipo de conhecimento gerado e disseminado pela televisão é um tipo de conhecimento conexial $^{36}$, isto é, um conhecimento cujas informações centrais são difusas, aparecem de forma fragmentada, mas ao mesmo tempo são unidades semânticas completas que apontam para outras fontes e cujo aprofundamento se dá pela leitura e pelo estudo. Embora se possa dizer que esse conhecimento é superficial, não se pode afirmar que ele é menos importante, pois é muitas vezes o ponto de partida para novas experiências culturais, da mesma forma que, outras vezes, consubstancia experiências já vividas.

32. MELO, José Marques de Melo. Estímulos ...op, cit.

33. MACHADO, Arlindo. A televisão levada a sério. São Paulo: Senac, 2000. p. 18.

34. BACCEGA. Maria Aparecida. Novela é cultura. Veja. 24/01/1996.

35. GARRIDO, Elza. TV imaginário e reflexão na formação de professores. Comunicação Apresentada no 11". Congresso de Leitura - COLE, Campinas/ SP, 15 a 18 jul. 1997.

36. A palavra inglesa link, no sentido em que é usada no jargão da internet, reflete melhor o tipo de conhecimento a que quero me referir. Como não há ainda em português o adjetivo linkado, usei conexial para indicar a teia de relações, de indicações, de links, que esse tipo de conhecimento suporta. 
À luz dessa conclusão, estou convencida de que posso falar numa transposição de fronteiras no que diz respeito às instâncias de letramento. A escola não é mais a agência de letramento por excelência e a televisão comercial, embora esteja destinada ao entretenimento e à informação geral, atua também como uma forte agência de letramento, para alguns, a principal, conforme demonstram o relato das pesquisas referidas.

\section{CONSIDERAÇÕES FINAIS}

A resposta formalmente apresentada na parte anterior, para a questão colocada no início deste trabalho, se insere numa discussão mais ampla sobre cultura/meios de comunicação e ensino. Só uma escola anacrônica, como disse Paulo Freire, vai optar por não enfrentar esta questão. Pode até adiar a resposta, fingir desconhecê-la, mas acredito que não será possível fugir dela. Se, por um lado, pode-se dizer que a "escola agoniza", em função dos seus métodos e recursos, por outro lado, a escola "pulsa de vida", pois as mensagens articuladas pelos novos meios de comunicação, especialmente pela televisão, teimam em ocupar a cena central, trazidas pelos alunos que, em geral, são mais sensíveis às novidades do que os professores.

Nesse embate, há um consenso entre muitos educadores e outros estudiosos: a televisão torna comum um repertório acessível a pessoas com as mais diferentes experiências culturais, mas há muitas controvérsias sobre a(s) forma(s) através das quais a escola deve se utilizar desse repertório. Provavelmente, as controvérsias continuarão se se esperar respostas uniformes. Elas deverão ser diversificadas, como convém a um veículo de subjetividades múltiplas e cuja recepção é também diversificada. Concordo com Figueiredo que "[se] torna necessário, como vêm ressaltando alguns estudiosos, que além do processo de alfabetização, no sentido de ensinar a ler o texto escrito, a escola assuma a tarefa de uma segunda alfabetização, ou seja, de ensinar a ler a mensagem midiática, compreender a sua linguagem, ultrapassando a ingenuidade que sustenta a ilusão da transparência entre a imagem e o real, porque a mídia não nos traz a realidade. Não se trata, entretanto, de assumir do ponto de vista paranóico que a rejeita em bloco, atribuindo-lhe o caráter de complô, como se os meios de comunicação fossem, apenas e o tempo todo, instrumentos de manipulação consciente do públicr - de falseamento do mundo". ${ }^{37}$

De $\therefore$ iorma e que faz sentido pensar numa escola que tenha uma postura crítica em relação à televisão visto que vai ter bases tanto para criticar os lugares-comuns (tantas vezes repetidos), mantendo um distanciamento em relação à repetição e à reprodução dessas idéias, como vai poder avaliá-los tecnicamente. A esse processo de alfabetização, conforme advertiu a autora, prefiro chamar de imersão no letramento proporcionado pela cultura midiática. Isso passa tanto pelo conhecimento de aspectos técnicos como pela apreciação de um bom repertório produzido por este meio. De acordo com Machado, a televisão pode ser abordada como 
um fenômeno de massa, de grande impacto na vida social e moderna; opção segundo a qual a televisão pode ser submetida a uma análise de tipo sociológico para verificar a extensão de sua influência. Por outro lado, a televisão pode ser abordada também como um dispositivo audiovisual através do qual uma civilização pode exprimir a seus contemporâneos os seus próprios anseios e dúvidas, as suas crenças e descrenças, as suas inquietações, as suas descobertas e os vôos de sua imaginação. Enveredando-se por essa segunda opção, a qualidade do material televisual bem como o tipo da sua intervenção passam a ser fundamentais para a análise e, nesse caso, a exposição a um repertório de qualidade é imprescindível. Apenas aqueles que rejeitam a priori a televisão é que não podem identificar nela programas de qualidade. É bem verdade que no Brasil eles são menos numerosos no quadro geral da programação que, como diria Boris Casoy, "tem de ser passado a limpo!".

Resumo: Este trabalho tem como objetivo apresentar argumentos que visam a auxiliar uma discussão mais pedagógica sobre a relação entre televisão e conhecimento. São quatro os argumentos principais que sustentam essa discussão. Primeiro, a televisão é um objeto de estudo, para isso são definidos os marcos teóricos que assim a caracterizam. Segundo, a televisão é uma instância enunciativo-discursiva. Terceiro, a cultura midiática, veiculada pela TV, influencia e é influenciada pela cultura letrada. Quarto, a escola deve assimilar e refletir sobre a cultura midiática, mas sem perder a sua especificidade de instância de formação e de transmissão do conhecimento.

Palavras-chave: cultura midiática, cultura letrada, programação de TV, escolarização, conhecimento
Longe de supor uma simbiose entre escola e televisão, considero como Citelli "a perspectiva segundo qual as instituições comunicativas e escolares tornaram-se lugares interdiscursivos que operam diálogos entre si, independentemente das possíveis assimetrias e desigualdades em suas condições de força. A proximidade não exclui os campos específicos onde atuam" ${ }^{38}$.

$\mathrm{O}$ atual momento da escola, ora de rejeição à televisão ora de receio de que esta ocupe um lugar que tradicionalmente é seu, é também da sociedade, que a despeito dos 50 anos da TV brasileira não tem com ela uma 'relação bem resolvida' e talvez seja cedo para isso. Se essa relação estivesse mais bem definida, certamente a problemática TV versus escola estaria melhor delineada. Concluindo, tenho a impressão, marcada pela minha experiência com a televisão e com a escola, que está última é como a Fênix. O mito anima-me à esperança: ela renascerá das cinzas, ainda mais forte!

\section{(TV as an instance of literacy)}

Abstract. This work aims at presenting arguments that hope to assist a more pedagogical discussion about the relationship between television and knowledge. There are four main arguments that support this discussion. First, television is an object of study; therefore, the theoretical marks that characterize it as such are defined. Second, television is an ennunciative-discursive instance. Third, the mediatic culture TV transmits influences and is influenced by the literate culture. Fourth, the school must assimilate and reflect on mediatic culture, but it must not loose its specificity as an instance of forming and transmitting knowledge.

Key words: mediatic culture, literate culture, TV programming, schooling, knowledge

38. CITELLI, Adilson. Comunicação e educação... op. cit. p. 143. 